\title{
Fingolimod additionally acts as immunomodulator focused on the innate immune system beyond its prominent effects on lymphocyte recirculation
}

Katja Thomas, Tony Sehr, Undine Proschmann, Francisco Alejandro Rodriguez-Leal, Rocco Haase and Tjalf Ziemssen ${ }^{*}(1)$

\begin{abstract}
Background: Growing evidence emphasizes the relevance of sphingolipids for metabolism and immunity of antigen-presenting cells (APC). APCs are key players in balancing tolerogenic and encephalitogenic responses in immunology. In contrast to the well-known prominent effects of sphingosine-1-phosphate (S1P) on lymphocyte trafficking, modulatory effects on APCs have not been fully characterized.

Methods: Frequencies and activation profiles of dendritic cell (DC) subtypes, monocytes, and T cell subsets in 35 multiple sclerosis (MS) patients were evaluated prior and after undergoing fingolimod treatment for up to 24 months. Impact of fingolimod and S1P on maturation and activation profile, pro-inflammatory cytokine release, and phagocytotic capacity was assessed in vitro and ex vivo. Modulation of DC-dependent programming of naïve CD4+ T cells, as well as CD4+ and CD8+ T cell proliferation, was also investigated in vitro and ex vivo.

Results: Fingolimod increased peripheral slanDC count-CD1+ DC, and monocyte frequencies remained stable. While CD4+ T cell count decreased, ratio of Treg/Th17 significantly increased in fingolimod-treated patients over time. CD83, CD150, and HLADR were all inhibited, but CD86 was upregulated in DCs after incubation in the presence of fingolimod. Fingolimod but not S1P was associated with reduced release of pro-inflammatory cytokines from DCs and monocytes in vitro and ex vivo. Fingolimod also inhibited phagocytic capacity of slanDCs and monocytes. After fingolimod, slanDCs demonstrated reduced potential to induce interferon-gamma-expressing Th1 or IL-17-expressing Th17 cells and DC-dependent T cell proliferation in vitro and in fingolimod-treated patients.

Conclusions: We present the first evidence that S1P-directed therapies can act additionally as immunomodulators that decrease the pro-inflammatory capabilities of APCs, which is a crucial element in DC-dependent T cell activation and programming.
\end{abstract}

Keywords: Innate immunity, Dendritic cells, Antigen-presenting cells, Sphingosine-1-phosphate-directed therapies, Multiple sclerosis

\footnotetext{
*Correspondence: Tjalf.Ziemssen@uniklinikum-dresden.de

Center of Clinical Neuroscience, Department of Neurology, Carl Gustav Carus

University Hospital, University of Technology Dresden, Fetscherstr. 74, 01307

Dresden, Germany
} 


\section{Background}

Multiple sclerosis (MS) is a chronic inflammatory disease of the central nervous system (CNS) that is mediated mainly by activated pro-inflammatory $\mathrm{CD} 4+\mathrm{T}$ helper (Th) cells and cytotoxic CD8+ T cells $[1,2]$. Growing evidence is available that suggest a role for antigen-presenting cells (APC) in the pathogenesis of MS via their extraordinary capacity for inducing and expanding pro-inflammatory $T$ cell populations $[3,4]$. In particular, dendritic cells (DC) play a crucial role in regulating the balance between encephalitogenic and tolerogenic immunity in MS [5]. We recently demonstrated the presence of 6-sulfo LacNAc+ (slan) DCs, which are the major pro-inflammatory and most potent $\mathrm{T}$ cellactivating DC populations, in active inflammatory MS lesions. SlanDCs represent a new potential link between innate and adaptive immunity in MS and are specifically modulated by different MS therapies [6, 7]. As such, future treatments should include targeted modulation of selective DC and APC functions [8, 9].

Fingolimod (FTY) is the first approved oral therapy for highly active relapsing remitting (RR) MS. Fingolimod exerts its effect via modulation of the sphingosine-1phosphate (S1P)-receptor (S1PR) [10, 11]. Extensive data on the mechanism of action of fingolimod demonstrate its principal effects on $\mathrm{T}$ and $\mathrm{B}$ cell trafficking via impairment of S1PR1-mediated recirculation, which results in significantly reduced lymphocyte egress from lymphoid tissues into the general circulation [12]. In addition to the effects on $\mathrm{T}$ and $\mathrm{B}$ cells, modulation of the innate immune system, including actions on DCs, have been proposed [13-17]. Sphingolipids and their G-proteincoupled receptors appear to play an important role in the modulation of the innate immune system. Additionally, all of the known sphingolipid receptor-subtypes (S1PR1-S1PR5) are apparently involved in the modulation of function and metabolism of APCs [13, 18, 19]. Although the circulation of APCs is not primarily regulated by the S1P-system, FTY and its active metabolite FTY-phosphate (FTYP) appear to affect APC migration into lymph nodes and tissues possibly via modulation of inflammatory chemokines [18, 20-22]. However, human data on effects of FTY on APC subsets in MS patients are rare, and the detailed impact on pro-inflammatory potential and $\mathrm{DC}$-dependent $\mathrm{T}$ cell regulation lack detailed understanding.

To gain novel insights into immunomodulatory effects of FTY on innate immunity beyond the established effects on lymphocyte recirculation, we investigated the FTY-stimulated ex vivo and in vitro modulation of frequency and function of slanDC (the most potent proinflammatory DC population) to evaluate the impact of FTY on inflammatory and $\mathrm{T}$ cell regulatory properties. Here, we present data on the impact of FTY on the inflammatory properties of slanDCs and classical APCs via in vitro and ex vivo analyses of FTY-treated MS patients.

\section{Methods \\ Patients and controls}

Blood samples of 35 RRMS patients diagnosed according to the McDonald criteria were used to evaluate immunomodulatory effects on APC during FTY treatment (Table 1). Blood samples were drawn prior to and during FTY treatment up to 24 months. Further blood samples were collected of ten untreated RRMS patients with stable disease course compared to ten RRMS patients with stable disease after 12 months of FTY therapy to perform additional ex vivo analyses. Blood of healthy donors was collected for in vitro analyses.

All experiments were approved by the institutional review board of the University Hospital of Dresden. All donors gave their written informed consent.

\section{Flow cytometric analysis}

Preparation of blood cells and analysis by fluorescenceactivated cell sorting (FACS) have been performed by a previously validated protocol defined by standard operating procedures (SOPs): Peripheral blood mononuclear cells (PBMCs) were prepared by Ficoll-Hypaque (Biochrom, Berlin, Germany) density centrifugation. Cell surface staining was performed by using fluorescencelabeled anti-CD3, anti-CD4, anti-CD8, anti-CD14, antiCD19, anti-CD40, anti-CD80, anti-CD83, anti-CD86, anti-CD150, anti-HLADR (BD Biosciences, Heidelberg, Germany), anti-BDCA1, anti-slan, or anti-CD39 (Miltenyi Biotec, Bergisch Gladbach, Germany) according to the manufacturer's instructions. Negative controls included directly labeled or unlabeled isotype-matched irrelevant antibodies (BD Biosciences). For further characterization of intracellular markers, PBMCs were suspended in culture medium consisting of RPMI 1640 (Biochrom), 5\% human AB serum (CC pro, Neustadt, Germany), $2 \mathrm{mM}$ L-glutamine, $100 \mathrm{U} / \mathrm{ml}$ penicillin, and $100 \mu \mathrm{g} / \mathrm{ml}$ streptomycin (Biochrom). Analysis of $\mathrm{T}$ regulatory cells (Treg cells) was performed directly, whereas Th17 cells were stimulated with $10 \mathrm{ng} / \mathrm{ml}$ phorbol myristate acetate (PMA, Sigma-Aldrich, Steinheim Germany) and $1 \mu \mathrm{g} / \mathrm{ml}$ ionomycin (Sigma-Aldrich) in the presence of $0.2 \mu \mathrm{M}$ Monensin (Biomol, Hamburg, Germany) for $6 \mathrm{~h}$ prior to analysis. For intracellular characterization of IL-17, CD154, and FoxP3, cells were fixed with fresh prepared fixation concentrate and permeabilized with wash-permeabilization concentrate (Fixation/Permeabilization Buffer Set, eBioscience). Subsequently, cells were stained using fluorescence labeled anti-IL-17 (BioLegend, London, UK), antiCD154 and anti-FoxP3 antibody (both Miltenyi 
Table 1 Patient characteristics

\begin{tabular}{|c|c|c|c|c|c|c|}
\hline Patient Nr. & Sex & Age & Disease duration [years] & Pretreatment & EDSS & Stable disease course \\
\hline 1 & $\mathrm{~F}$ & 23 & 3 & Interferon-beta & 1.5 & Yes \\
\hline 2 & $\mathrm{~F}$ & 54 & 9 & None & 2 & Yes \\
\hline 3 & M & 28 & 4 & Interferon-beta & 1.5 & Yes \\
\hline 4 & M & 33 & 14 & Natalizumab & 4 & Yes \\
\hline 5 & $\mathrm{~F}$ & 42 & 14 & Glatiramer acetate & 3 & Yes \\
\hline 6 & $\mathrm{~F}$ & 53 & 16 & Interferon-beta & 3.5 & Yes \\
\hline 7 & $\mathrm{~F}$ & 47 & 3 & Interferon-beta & 3 & Yes \\
\hline 8 & $\mathrm{~F}$ & 47 & 7 & Interferon-beta & 2 & Yes \\
\hline 9 & $\mathrm{~F}$ & 41 & 11 & Interferon-beta & 6 & Yes \\
\hline 10 & $\mathrm{~F}$ & 46 & 15 & Natalizumab & 4 & Yes \\
\hline 11 & $\mathrm{~F}$ & 42 & 2 & None & 1 & Yes \\
\hline 12 & $\mathrm{~F}$ & 19 & 2 & None & 1.5 & Yes \\
\hline 13 & $\mathrm{~F}$ & 30 & 11 & Natalizumab & 2 & Yes \\
\hline 14 & M & 35 & 3 & Glatiramer acetate & 2 & Yes \\
\hline 15 & M & 27 & 3 & Glatiramer acetate & 2 & Yes \\
\hline 16 & $\mathrm{~F}$ & 44 & 4 & Interferon-beta & 2.5 & Yes \\
\hline 17 & $\mathrm{~F}$ & 27 & 11 & Natalizumab & 2 & No \\
\hline 18 & $\mathrm{~F}$ & 29 & 15 & Natalizumab & 6 & Yes \\
\hline 19 & $\mathrm{~F}$ & 24 & 11 & None & 1 & Yes \\
\hline 20 & $\mathrm{~F}$ & 47 & 6 & Glatiramer acetate & 3 & Yes \\
\hline 21 & $\mathrm{~F}$ & 45 & 11 & Glatiramer acetate & 1.5 & Yes \\
\hline 22 & M & 42 & 3 & Glatiramer acetate & 4 & Yes \\
\hline 23 & $\mathrm{~F}$ & 44 & 10 & Interferon-beta & 1.5 & Yes \\
\hline 24 & M & 38 & 3 & Glatiramer acetate & 1.5 & Yes \\
\hline 25 & M & 26 & 4 & Interferon-beta & 1.5 & No \\
\hline 26 & $\mathrm{~F}$ & 42 & 4 & Glatiramer acetate & 2 & Yes \\
\hline 27 & M & 29 & 2 & Glatiramer acetate & 2 & Yes \\
\hline 28 & $\mathrm{~F}$ & 35 & 2 & Glatiramer acetate & 3 & Yes \\
\hline 29 & M & 41 & 1 & None & 2 & Yes \\
\hline 30 & M & 30 & 6 & Interferon-beta & 1.5 & Yes \\
\hline 31 & M & 28 & 1 & None & 1.5 & Yes \\
\hline 32 & M & 44 & 10 & Interferon-beta & 4 & Yes \\
\hline 33 & $\mathrm{~F}$ & 45 & 10 & Interferon-beta & 4 & Yes \\
\hline 34 & M & 41 & 19 & Natalizumab & 3 & Yes \\
\hline 35 & $\mathrm{~F}$ & 33 & 8 & Glatiramer acetate & 2.5 & Yes \\
\hline
\end{tabular}

Sex, age at FTY start, time from disease onset to FTY start, pretreatment, baseline EDSS, and disease course (stable versus not stable) are depicted

Biotec), or isotype-matched irrelevant antibody (BD Biosciences). After the staining procedure, cells were evaluated on a FACScan Calibur (BD Bioscience). Exact preparation of the cells, staining protocol, and procedure as well as adjustment and compensation of the FACScan was established prior to first analysis of samples. Complete blood cell count was performed additionally to FACS analysis. No patients with lymphopenia $<0.2 \mathrm{GPt} / \mathrm{l}$ or lower medical drug possession rate $>95 \%$ during fingolimod treatment were included to guarantee reliable data.

\section{Immunomagnetic cell sorting}

Isolation of slanDCs was performed as described previously [6]. PBMCs were incubated with M-DC8 hybridoma supernatant containing $10 \mu \mathrm{g} / \mathrm{ml}$ of antibody and additional rat anti-mouse IgM paramagnetic microbeads (Miltenyi Biotec). Cells were sorted on two columns via 
the autoMACS device (Miltenyi Biotec, Bergisch Gladbach, Germany). CD1 + DC were sorted by depletion of CD19+ cells first, followed by positive selection of BDCA1+ using immunomagnetic separation according to the manufacturer's instructions (Miltenyi Biotec, Bergisch Gladbach, Germany). CD14+ monocytes were isolated by positive selection, and CD4+ T cells, CD8+ T cells, and naive CD45RA + CD4+ T cells were isolated by depletion using immunomagnetic separation (Miltenyi Biotec, Bergisch Gladbach, Germany). The purity of the isolated cell populations was $>95 \%$ as always assessed by flow cytometry afterwards.

\section{Cytokine assay}

Sorted slanDCs, CD1 + DCs, and monocytes of untreated or FTY-treated patients were cultured for $24 \mathrm{~h}$. For the last $18 \mathrm{~h}$, lipopolysaccharide (LPS, Sigma Aldrich) was added to stimulate cytokine release by TLR4 activation; unstimulated cells served as control. Additionally, cells of healthy controls and FTY-treated patients were maintained in the presence or absence of $30 \mathrm{ng} / \mathrm{ml}$ FTY, $30 \mathrm{ng} / \mathrm{ml}$ FTYP (Caltag, Buckingham, UK), or 20 or $200 \mathrm{nM} \mathrm{S1P}$ (Sigma Aldrich) in culture before LPS was added. Supernatants were collected, and the concentration of tumor necrosis factor alpha (TNFalpha), IL-1beta, IL-6, IL-12, and IL-23 was determined using a commercial ELISA kit (BD Biosciences) according to the manufacturer's instructions.

\section{Maturation and activation profile}

Sorted slanDCs, CD1+ DCs, and monocytes of healthy controls or FTY-treated patients were cultured in the presence or absence of $30 \mathrm{ng} / \mathrm{ml} \mathrm{FTY} \mathrm{or} 30 \mathrm{ng} / \mathrm{ml} \mathrm{FTY-}$ phosphate or 20 or $200 \mathrm{nM} \mathrm{S1P}$ in vitro. Cells were collected and characterized with regard to surface activation and maturation markers by staining with fluorescence labeled anti-CD40, anti-CD80, anti-CD83, anti-CD86, anti-CD150, and anti-HLA-DR (BD Biosciences). Cells were evaluated on a FACScan Calibur.

\section{DC-depending $\mathrm{T}$ cell proliferation and programming}

SlanDCs or CD1 + DCs of healthy controls were cultured with or without 3 or $30 \mathrm{ng} / \mathrm{ml} \mathrm{FTY} \mathrm{or} \mathrm{FTYP} \mathrm{for}$ $6 \mathrm{~h}$ and washed with phosphate-buffered saline (PBS, Sigma Aldrich). To evaluate T cell proliferation, allogeneic $\mathrm{CD} 4+\mathrm{T}$ cells or $\mathrm{CD} 8+\mathrm{T}$ cells were labeled with carboxyfluorescein-di-acetate- $N$-succinimidylester

(CFSE, Molecular Probes, Eugene, USA) at a final concentration of $0.3 \mu \mathrm{M}$. Treated and untreated DCs $(1 \times$ $10^{4}$ cells/well) were co-cultured with CFSE-labeled allogeneic CD4+ T cells or CD8+ T cells $\left(1 \times 10^{5}\right.$ cells/well $)$ for 4 days. Cells were harvested, and proliferation was calculated by CFSE-incorporation by flow cytometry and quantified by cell division index (CDI). For ex vivo analyses, slanDCs of FTY-treated patients compared to healthy controls were co-cultured with CFSE-labeled allogeneic $\mathrm{CD} 4+$ or $\mathrm{CD} 8+\mathrm{T}$ cells of the same healthy donor to compare different potentials to induce $\mathrm{T}$ cell proliferation. To assess direct effects of FTY or FTYP on $\mathrm{T}$ cells, sorted CFSE-labeled CD4+ T cells or CD8+ T cells of healthy donors or FTY-treated patients were cultured in the presence of $5 \mu \mathrm{g} / \mathrm{ml}$ human anti-CD3 and $1 \mu \mathrm{g} / \mathrm{ml}$ human anti-CD28 (both BD Bioscience) without or with FTY or FTYP for 4 days. CFSE-incorporation was evaluated and counted as described above.

To evaluate DC-dependent T cell programming, FTY or FTYP pretreated and untreated slanDCs or CD1 + DC $\left(1 \times 10^{4}\right.$ cells/well $)$ of healthy controls were cocultured with allogeneic naïve CD45RA + CD4+ T cells $\left(1 \times 10^{5}\right.$ cells/well $)$ in the presence of LPS for 8 days. Thereafter, T cells were stimulated with $10 \mathrm{ng} / \mathrm{ml}$ PMA and $1 \mu \mathrm{g} / \mathrm{ml}$ ionomycin in the presence of $0.2 \mu \mathrm{M}$ monensin for $4 \mathrm{~h}$. For intracellular characterization of IFNgamma, IL-17 and IL-4 production, cells were fixed with freshly prepared ice-cold 4\% paraformaldehyde (Merck) and permeabilized with $0.1 \%$ saponin (Merck) in PBS containing $1 \%$ fetal calf serum (FCS, Biochrom). Subsequently, cells were stained using fluorescence-labeled anti-IFN-gamma, anti-IL-17, and anti-IL-4 antibody or isotype-matched irrelevant antibody (BD Biosciences). After the staining procedure, cells were evaluated on a LSR Fortessa (BD Bioscience). For ex vivo analyses, slanDCs of FTY-treated patients compared to healthy controls were co-cultured with naïve CD45RA+ CD4+ T cells of the same healthy donor to compare different potential in $\mathrm{T}$ cell programming. To compare impact of FTY or FTYP on potential of polarization directly on $\mathrm{T}$ cells, naïve CD45RA $+\mathrm{CD} 4+\mathrm{T}$ cells stimulated with $5 \mu \mathrm{g} / \mathrm{ml}$ human anti-CD3 and $1 \mu \mathrm{g} / \mathrm{ml}$ human antiCD28 treated without or with FTY or FTYP served as control. Differentiation into Th1 T cells was induced by adding $10 \mathrm{ng} / \mathrm{ml}$ human IL-12 and $10 \mu \mathrm{g} / \mathrm{ml}$ human anti-IL4, whereas Th2 differentiation was ensured by adding $10 \mathrm{ng} / \mathrm{ml}$ human IL-4 and $10 \mu \mathrm{g} / \mathrm{ml}$ human antiIFN-gamma (all R\&D Systems). After 8 days of cell culture, $\mathrm{T}$ cells were prepared and analyzed as described above.

\section{Phagocytosis assay}

Sorted slanDCs, CD1+ DCs, and CD14+ monocytes of healthy donors were maintained for $12 \mathrm{~h}$ in the presence or absence of $3 \mathrm{ng} / \mathrm{ml}$ or $30 \mathrm{ng} / \mathrm{ml}$ of FTY or FTYP in culture. To analyze, phagocytotic ability cells were treated with $1 \mu \mathrm{m}$ carboxylate-modified yellow-green fluorescent FluoSpheres beads (Thermo Fisher Scientific, MA, USA) for $60 \mathrm{~min}$ at $37^{\circ} \mathrm{C}$. After cells were washed with PBS, incorporation of beads was evaluated by FACScan Calibur. 


\section{Apoptosis assay}

Sorted slanDCs, CD1 + DCs, and CD14+ monocytes of healthy donors were cultured for 24 or $48 \mathrm{~h}$ in the presence or absence of different concentrations of FTY or FTYP (3 ng/ml; $30 \mathrm{ng} / \mathrm{ml}$ ). Annexin was measured using a FITC-labeled antibody (BD Bioscience) to determine apoptosis at early stage, and APC-labeled fixable viability dye staining (BD Bioscience) was used to evaluate apoptosis at late stage characterized by DNA fragmentation. After, staining cells were analyzed by FACScan Calibur.

\section{Statistical analysis}

For repeated measure testing, repeated measure analysis of variance (ANOVA) with Bonferroni's correction for compared pairs was used. Analyses with multiple comparisons but not repeated testing were evaluated by ANOVA with Bonferroni's correction. Analyses without multiple testing were assessed by Student's $t$ test. Values of $" p<0.05,{ }^{* *} p<0.01$, and **:* $p<0.001$ were considered significant.

\section{Results}

Increase in slanDC frequency in comparison to T cell frequency changes in peripheral blood compartment during long-term FTY treatment

In FTY-treated RRMS patients, there was a relative and absolute increase of slanDCs frequency starting after treatment initiation and during follow-up of 24 months (Fig. 1a (A/B)). In contrast, CD1 + DCs and monocytes increased in relative but not in absolute frequency (Fig. 1a (C-F)). While CD4+ T cell levels significantly decreased from the start of treatment on (Fig. 1a (G)), there was a gradual reduction of the proportion of CD154+ IL17+ Th17 cells over time. The proportion of CD39+ FoxP3+ Treg cells gradually increased (Fig. 1a $(\mathrm{H} / \mathrm{I}))$. Therefore, an increase in the ratio of Treg/Th17 could be observed during the first year of FTY treatment (Fig. 1a (K)).

\section{Decrease of activation/maturation markers and pro- inflammatory cytokine secretion in slanDCs during long- term FTY treatment}

During FTY treatment, a decreased ex vivo surface expression of CD83, CD150, and HLADR on APCs over the 24 months could be described (Fig. 1b). All DC subsets showed an increase of CD86 (Fig. 1b (C/G)), which remained unchanged in monocytes (Fig. 1b (L)). CD80 expression was downregulated in slanDCs but not in $\mathrm{CD} 1+\mathrm{DCs}$ and monocytes (Fig. 1b (D/H/M)). CD40 was unaffected in all investigated APC subsets (data not shown).

SlanDCs of untreated RRMS patients presented with higher levels of expression of IL-1beta, TNF-alpha as well as IL-12 and IL-23 compared to cells from FTY- treated patients (Table 2). In CD1 + DCs from FTYtreated patients, there was no modulation of IL-12 and IL-23 release upon stimulation compared to untreated MS patients (Table 2). Production of IL-6 by slanDCs and CD1 + DCs was lower in FTY-treated patients compared with controls, but differences did not reach statistical significance (Table 2). In monocytes from FTYtreated patients, release of IL-1beta and TNF-alpha was also inhibited, whereas IL-6 secretion was unchanged (Table 2).

Different in vitro modulation of activation markers and cytokine secretion by FTY and FTYP in different APCs

Evaluating effects of FTY or FTYP in vitro and sorted APC of healthy controls were co-incubated with FTY and FTYP: SlanDCs, but not CD1 + DCs, decreased their CD83 expression in response to FTY and FTYP (Table 3). Upregulation of activation marker CD150 in treated monocytes was significantly impaired after FTY or FTYP co-incubation compared with untreated controls (Table 3). No significant alteration in HLADR, CD86, CD80, or CD40 expression could be shown in any investigated cells after FTY or FTYP co-culture in vitro (Table 3).

In vitro addition of FTY and FTYP reduced IL-1beta, IL-6, TNF-alpha, IL-12, and IL-23 secretion in slanDCs compared with untreated controls (Table 3). Interestingly, FTY exerted a stronger suppressive effect than FTYP (Table 3). In CD1+ DCs, only IL-1beta and TNFalpha but not IL-12 and IL-23 cytokine production was reduced by FTY and FTYP in vitro (Table 3). IL-6 was inhibited significantly only by FTY (Table 3 ). Both FTY and FTYP significantly inhibited pro-inflammatory in vitro cytokine release of IL-1beta, IL-6, and TNF-alpha in monocytes compared with untreated controls (Table 3).

\section{SlanDC are modulated by S1P in healthy donors but not FTY-treated patients}

In similar in vitro experiments, S1P modulated the expression of HLADR, CD86, and CD40 but not CD83 or CD80 on slanDCs of healthy donors (Fig. 2a) or of surface markers on CD1+ DCs and monocytes of healthy controls (data not shown). Interestingly, in further ex vivo analyses, sorted slanDCs of FTY-treated patients that were cultured in the presence or absence of 20 or $200 \mathrm{nM}$ S1P did not present any additional changes in surface expression of activation or maturation markers (Fig. 2b). Neither sorted CD1+ DC nor sorted monocytes of FTY-treated patients were affected with respect to the expression of surface markers after culture in the presence of S1P (data not shown). There was no impact of 20 or $200 \mathrm{nM} \mathrm{S1P}$ on pro-inflammatory cytokine release in sorted slanDCs, CD1+ DCs, or monocytes of 
(a)
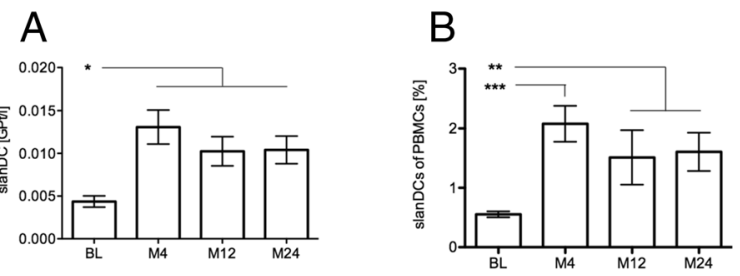

C

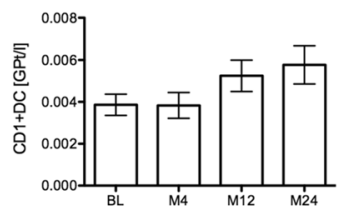

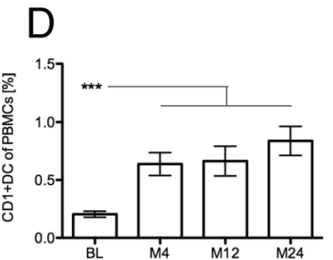
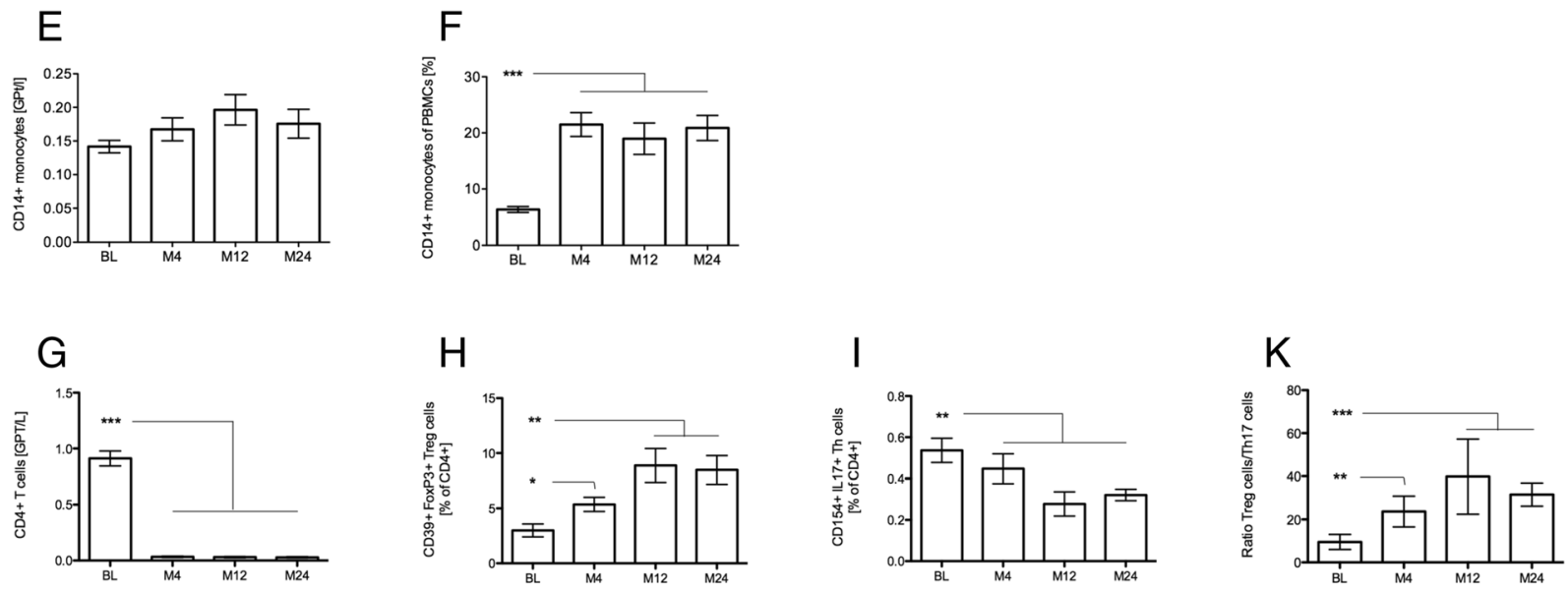

(b)

A
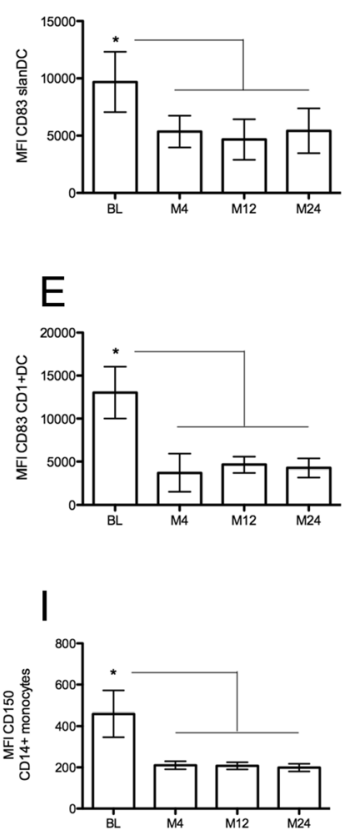

B

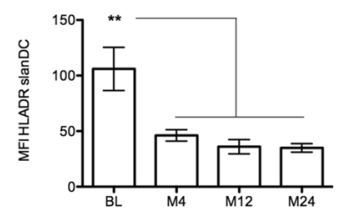

E
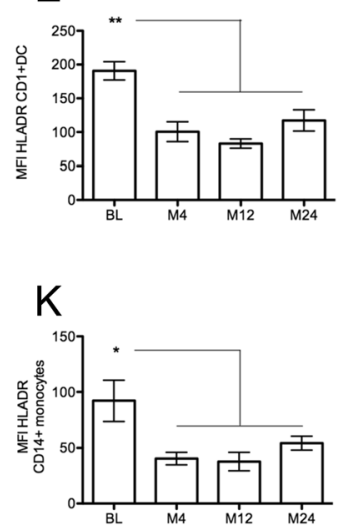
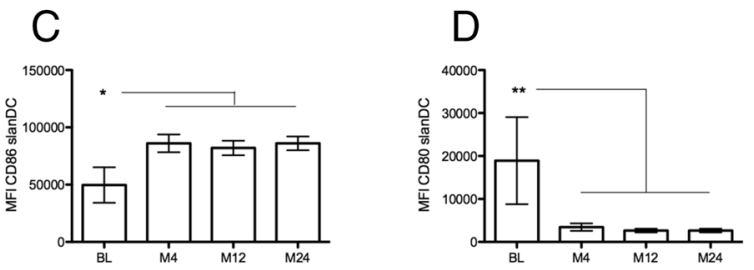

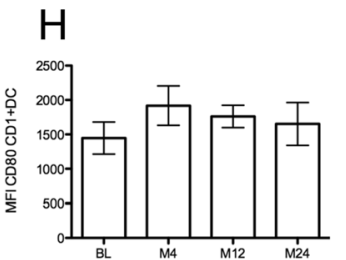

L

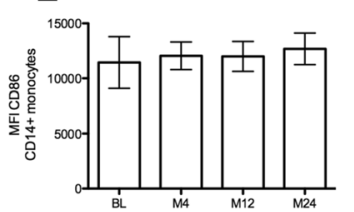

\section{M}

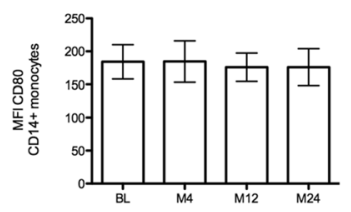

Fig. 1 APC and T cell count in FTY-treated RRMS patients. a Relative and absolute cell count in slanDCs (A/B), CD1 + DCs (C/D), and monocytes (E/F) were evaluated at baseline (BL), 4, 12, and 24 months (M) follow-up of 35 FTY-treated RRMS patients. In parallel absolute cell count of CD4+ T cells, proportion of CD39 + FoxP3+ Treg cells and CD154 + IL17+ Th17 cells was examined (G-I). Ratio of Treg/Th17 is depicted (K). b Activation and maturation markers of APC during FTY treatment. Expression of activation and co-stimulatory surface markers were analyzed at baseline (BL), 4, 12, and 24 months (M) in FTY-treated RRMS patients in slanDCs $(A-D), C D 1+D C s(E-H)$, and monocytes $(I-M)$. Mean values \pm SEM are presented. Bonferroni's correction for compared pairs was used for multiple testing. Asterisks indicate a statistically significant difference $\left.{ }^{*} p<0.05,{ }^{* *} p<0.01,{ }^{* * *} p<0.001\right)$ 
Table 2 Cytokine release of APC during FTY treatment

\begin{tabular}{|c|c|c|c|c|}
\hline APC subtype & Cytokine & MS CTRL & MS FTY & $p$ value \\
\hline \multirow[t]{5}{*}{ slanDC } & IL-1 beta & $13,992.8(+/-3452.7)$ & $3762.3(+/-1773.8)$ & $<0.01$ \\
\hline & IL-6 & $68,729.8(+/-22,461.7)$ & $52,339.4(+/-23,723.3)$ & n.s. \\
\hline & TNF-alpha & $41,189.0(+/-7526.0)$ & $18,302.1(+/-6363.5)$ & $<0.05$ \\
\hline & $\mid \mathrm{L}-12$ & $484.9(+/-99.3)$ & $179.7(+/-44.6)$ & $<0.05$ \\
\hline & IL-23 & $3298.2(+/-990.9)$ & $1304.6(+/-326.2)$ & $<0.05$ \\
\hline \multirow[t]{5}{*}{$C D 1+D C$} & IL-1beta & $405.1(+/-48.3)$ & $255.7(+/-57.4)$ & $<0.05$ \\
\hline & IL-6 & $7556.1(+/-3401.0)$ & $5270.4(+/-2260.8)$ & n.s. \\
\hline & TNF-alpha & $1190.7(+/-289.7)$ & $653.1(+/-19.6)$ & $<0.05$ \\
\hline & $\mid \mathrm{L}-12$ & $166.1(+/-54.0)$ & $182.3(+/-42.9)$ & n.s. \\
\hline & IL-23 & $213.2(+/-15.9)$ & $188.7(+/-28.8)$ & n.s. \\
\hline \multirow[t]{3}{*}{ Monocytes } & IL-1 beta & $6517.8(+/-1073.1)$ & $4300.2(+/-620.1)$ & $<0.05$ \\
\hline & IL-6 & $110,065.0(+/-17,602.5)$ & $106,537.0(+/-23,730.0)$ & n.s. \\
\hline & TNF-alpha & $9018.8(+/-2753.8)$ & $4841.4(+/-809.6)$ & $<0.05$ \\
\hline
\end{tabular}

Sorted slanDCs, CD1 + DCs, and monocytes of each ten untreated (MS CTRL) and FTY-treated (MS FTY) RRMS patients were stimulated to induce and analyze cytokine release. Mean values of cytokines in picograms per milliliter are presented, and $p$ values indicate level of statistical significance n.s. not statistically significant

healthy controls or FTY-treated patients in vitro (data not shown).

\section{Modulation of DC-dependent T cell proliferation and polarization in vitro and in FTY-treated patients without any direct effects on $\mathrm{T}$ cells}

In vitro pretreatment with FTY and, to a lower extent, FTYP of slanDC and CD1 + DC demonstrated a decrease in $\mathrm{DC}$-dependent $\mathrm{T}$ cell proliferation in a dose-depending manner in CD4+ T cells rather than in CD8+ T cells (Fig. 3a (A-D)). FTY and FTYP pretreated sorted slanDCs and CD1 + DCs were significantly inhibited in their ability to promote their typical differentiation of naïve CD45RA+ CD4+ T lymphocytes into pro-inflammatory IFN-gammaexpressing Th1 cells or IL-17-expressing Th17 cells (Fig. 3a $(\mathrm{E}-\mathrm{H})$ ), whereas pretreatment of CD1 + DCs with FTYP showed no significant influence (Fig. 3b $(\mathrm{G} / \mathrm{H})$ ). Differentiation toward anti-inflammatory Th2 cells releasing IL-4 was not modulated by FTY or FTYP pretreatment of slanDC or CD1 + DC in vitro (data not shown).

These results were mirrored in slanDCs of FTYtreated patients ex vivo: SlanDCs of FTY-treated patients induced less proliferation in allogenic CD4+ or CD8+ T cells compared to slanDCs from healthy controls (Fig. 3b (A/B)). Compared to healthy controls, slanDCs of FTYtreated patients were impaired in their induction of differentiation of naïve CD45RA+ CD4 T cells into proinflammatory IFN-gamma-releasing Th1 cells or IL17releasing Th17 cells (Fig. 3b (C/D)), whereas differentiation into Th2 cells was again unaffected (data not shown).

In contrast, neither FTY nor FTYP directly affected $\mathrm{CD} 4+$ or $\mathrm{CD} 8+\mathrm{T}$ cell proliferation in vitro (Fig. 3c (A/
B)). FTY or FTYP did not directly affect any polarization of naïve CD45RA+CD4+ T lymphocytes into IFNgamma-expressing Th1 cells, IL-17 releasing Th17 (Fig. 3c $(\mathrm{C} / \mathrm{D})$ ), or IL-4 releasing Th2 cells (data not shown). Furthermore, CD4+ and CD8+ T cells of FTYtreated patients demonstrated similar proliferative capacity after CD3/CD28 stimulation compared to healthy controls (Fig. 3d (A/B)).

FTY exerts differential effects on phagocytic function, but not on apoptosis of APC

In slanDCs and monocytes, but not in CD1+ DCs, phagocytic capacity was significant and dose depending inhibited by FTY and FTYP (Fig. 4a (A-C)). In contrast to phagocytic function, neither FTY nor FTYP increased apoptosis in any investigated APCs within all investigated time intervals (Fig. 4b (A-C)).

\section{Discussion}

A growing number of studies highlight the relevance of sphingolipids and their related pathways that regulate innate immunity $[13,17,18]$. Due to their characteristic properties of antigen uptake and antigen presentation to T cells, DCs are particular key players in balancing tolerogenic and immunogenic immune responses [5]. Many studies hint at the importance of APCs, and particularly DCs, in the pathogenesis of MS by virtue of the initiation and perpetuation of $\mathrm{T}$ cell responses in periphery as well as in the CNS [3, 6-9]. Growing evidence supports the concept of distinct modulation of innate immune cells in S1PR-focused therapies beyond their effects on lymphocyte recirculation $[14,17,18]$. 
Table 3 Cytokine release and activation/maturation markers after FTY or FTYP in vitro

\begin{tabular}{|c|c|c|c|c|c|c|}
\hline APC subtype & Cytokine & Without & FTY & $p$ value & FTYP & $p$ value \\
\hline \multirow[t]{5}{*}{ slanDC } & IL-1 beta & $26,753.7(+/-13,156.6)$ & $750.8(+/-277.3)$ & $<0.05$ & $6835.1(+/-2634.6)$ & $<0.05$ \\
\hline & IL-6 & $69,634.3(+/-18,883.2)$ & $7180.5(+/-1748.1)$ & $<0.05$ & $46,643.9(+/-8215.2)$ & $<0.05$ \\
\hline & TNF-alpha & 18,837.0 (+/-9012.4) & $1576.9(+/-267.4)$ & $<0.05$ & $5960.4(+/-2131.8)$ & $<0.05$ \\
\hline & IL-12 & $637.7(+/-141.8)$ & $92.2(+/-19.5)$ & $<0.01$ & $312.8(+/-153.3)$ & n.s. \\
\hline & IL-23 & $4423.2(+/-2068.8)$ & $136.9(+/-29.9)$ & $<0.05$ & $1919.4(+/-644.6)$ & $<0.05$ \\
\hline \multirow[t]{5}{*}{$C D 1+D C$} & IL-1 beta & $624.4(+/-282.8)$ & $266.2(+/-37.1)$ & $<0.05$ & $284.3(+/-15.7)$ & $<0.05$ \\
\hline & IL-6 & $6889.3(+/-1367.2)$ & $1259.1(+/-91.5)$ & $<0.01$ & $5413.8(+/-1100.4)$ & n.s. \\
\hline & TNF-alpha & $2203.0(+/-1140.7)$ & $933.9(+/-387.3)$ & $<0.05$ & $468.6(+/-37.9)$ & $<0.05$ \\
\hline & IL-12 & $74.8(+/-20.5)$ & $66.4(+/-6.6)$ & n.s. & $66.3(+/-7.2)$ & n.s. \\
\hline & IL-23 & $250.7(+/-36.1)$ & $251.2(+/-61.7)$ & n.s. & $189.1(+/-22.9)$ & n.s. \\
\hline \multirow[t]{3}{*}{ Monocytes } & IL-1beta & 8670.9 (+/-4065.2) & $4902.8(+/-1932.1)$ & $<0.05$ & $599.8(+/-113.4)$ & $<0.05$ \\
\hline & IL-6 & $105,741.0(+/-24,004.5)$ & $31,584.8(+/-11,302.5)$ & $<0.05$ & $32,223.6(+/-8824.4)$ & $<0.05$ \\
\hline & TNF-alpha & $2050.2(+/-622.3)$ & $1149.2(+/-345.7)$ & n.s. & $705.1(+/-164.8)$ & $<0.05$ \\
\hline APC subtype & Surface marker & Without & FTY & $p$ value & FTYP & $p$ value \\
\hline \multirow[t]{5}{*}{ slanDC } & CD83 & $866.6(+/-88.9)$ & $426.8(+/-34.5)$ & $<0.05$ & $477.5(+/-63.7)$ & $<0.05$ \\
\hline & HLADR & $243.1(+/-40,9)$ & $254.7(+/-56,7)$ & n.s. & $300.0(+/-73,5)$ & n.s. \\
\hline & CD86 & $681.6(+/-115.1)$ & $571.6(+/-105.9)$ & n.s. & $670.3(+/-105.4)$ & n.s. \\
\hline & CD80 & $896.5(+/-42.3)$ & $812.5(+/-39.1)$ & n.s. & $906.5(+/-63.7)$ & n.s. \\
\hline & CD40 & $510.0(+/-72.9)$ & $573.4(+/-100.1)$ & n.s. & $542.5(+/-90.2)$ & n.s. \\
\hline \multirow[t]{5}{*}{$C D 1+D C$} & CD83 & $720.9(+/-135.9)$ & $587.8(+/-128.7)$ & n.s. & $707.0(+/-111.3)$ & n.s. \\
\hline & HLADR & $405.3(+/-94.0)$ & $418.0(+/-63.5)$ & n.s. & $327.4(+/-75.7)$ & n.s. \\
\hline & CD86 & $810.8(+/-189.2)$ & $703.3(+/-64.8)$ & n.s. & $893.4(+/-197.2)$ & n.s. \\
\hline & CD80 & $632.8(+/-61.7)$ & $588.5(+/-45.7)$ & n.s. & $601.5(+/-23.6)$ & n.s. \\
\hline & CD40 & $556.5(+/-44.3)$ & $650.0(+/-75.6)$ & n.s. & $578.6(+/-50.8)$ & n.s. \\
\hline \multirow[t]{5}{*}{ Monocytes } & CD150 & $253.2(+/-23.8)$ & $80.7(+/-8.3)$ & $<0.05$ & $106.8(+/-5.9)$ & $<0.05$ \\
\hline & HLADR & $131.1(+/-17.7)$ & $177.0(+/-36.5)$ & n.s. & $109.1(+/-18.5)$ & n.s. \\
\hline & CD86 & $295.8(+/-27.0)$ & $352.0(+/-36.7)$ & n.s. & $243.6(+/-25.9)$ & n.s. \\
\hline & CD80 & $165.8(+/-29.6)$ & $171.3(+/-15.6)$ & n.s. & $162.8(+/-22.4)$ & n.s. \\
\hline & CD40 & $395.0(+/-49.7)$ & $459.5(+/-58.2)$ & n.s. & $332.1(+/-47.7)$ & n.s. \\
\hline
\end{tabular}

Sorted slanDCs, CD1+ DCs, and monocytes of eight healthy donors were stimulated in the absence (without) or presence of $30 \mathrm{ng} / \mathrm{ml} \mathrm{FTY} \mathrm{or} \mathrm{FTYP.} \mathrm{Release} \mathrm{of} \mathrm{pro-}$ inflammatory cytokines and expression of surface maturation/activation markers was then evaluated. Mean values of cytokines in picograms per millliliter or MFI of surface expression are presented, Bonferroni's correction was used for multiple testing, and $p$ values indicate level of statistical significance n.s. not significant

During long-term follow-up, the relative number of peripheral slanDCs, CD1+ DCs, and monocytes increased in FTY-treated patients. These effects are in line with the redistribution of peripheral lymphocytes during FTY treatment. But the absolute number of slanDCs also increased. Expression of S1PR1-S1PR4 on monocytederived DC surfaces has been investigated, and S1PR4 appears to be one of the dominant receptors subtypes in that environment [19]. The impact of FTY and S1PR agonists on APC migration are contradictory and seem to depend on maturation and differentiation [18, 22, 23]. Some reports have shown an increase in peripheral DC numbers in mice, combined with a decrease in the number of DCs in lymph nodes, thereby suggesting a downregulation of CCR7-but not S1PR1-during FTY treatment [18, 20, 22-24]. Additionally, reduced migration of DCs in the presence of certain chemokines after FTY has been shown, and this indicates the possibility of inhibited DC migration into the CNS in inflammatory conditions such as those seen in active MS [20, 24]. Different studies demonstrated significant expression of S1PR1-4 on human and murine DC subtypes [16, 23, 25]. Systemic FTY administration leads to a decrease in expression of surface adhesion molecules and chemokine receptors including CCR7, which are essential for a variety of migratory processes $[20,23]$. S1PR agonism impaired DCs in activation and differentiation, which is important to upregulate adhesion molecules and 
(a)
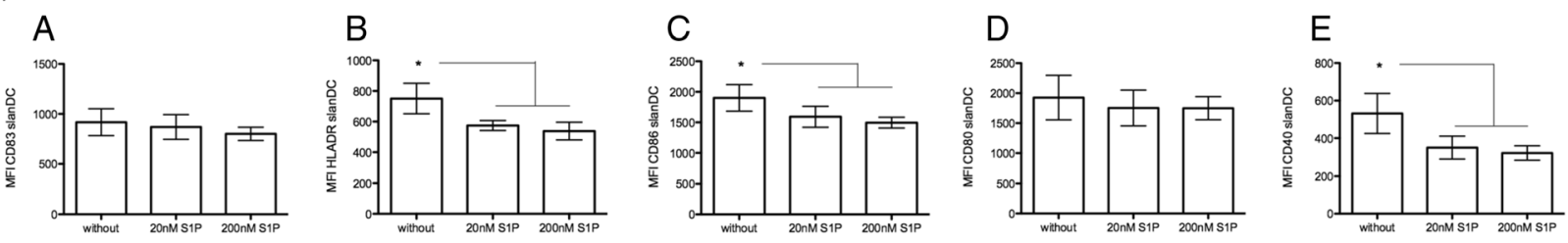

(b)
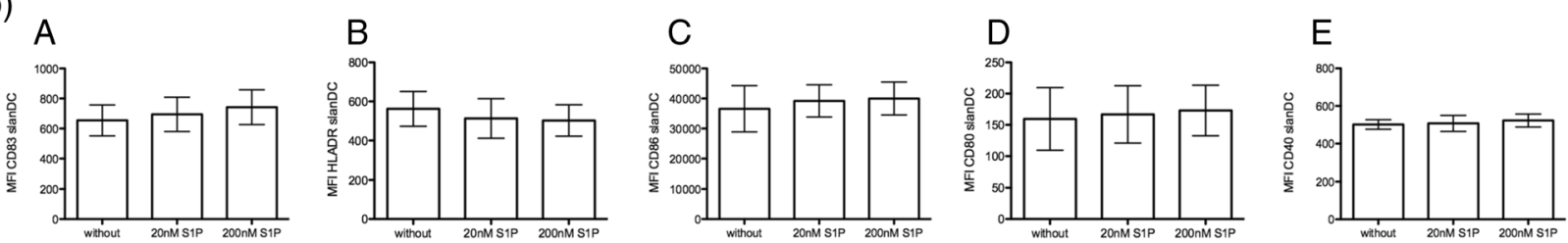

Fig. 2 Activation and maturation marker after S1P. a Sorted slanDCs $(A-E)$ of healthy donors were cultured in the absence (without) or presence of 2 or 200 nM S1P. Expression of activation and maturation surface markers was analyzed. $\mathbf{b}$ Sorted slanDCs (A-E) of FTY-treated MS patients were cultured in the absence (without) or presence of 20 or 200 nM S1P. Expression of activation and maturation surface markers was analyzed. Mean values \pm SEM of eight individual experiments are presented. Bonferroni's correction was used. Asterisks indicate statistically significant difference $\left({ }^{*} p<0.05\right)$

chemokine receptors as well $[16,23]$. Reduced expression of these markers contributes to a decreased homing of DCs into lymphoid organs, but into inflamed tissues. These findings indicate that DC migration is additionally controlled by S1PRs and affected by S1PR-targeted therapies that account for increase in peripheral absolute DC count in our and recent study [20,23]. Further studies are needed to investigate the exact effect of FTY and its homologues on migration of slanDCs or other dendritic cells.

Due to the established effects of FTY on lymphocyte recirculation, CD4+ T cell counts decreased in our FTYtreated patients. But among $\mathrm{CD} 4+\mathrm{T}$ cells exposed to FTY, the proportion of Th17 cells was reduced, while Treg cell numbers increased, thereby increasing the Treg/Th17 cell ratio of cells. These data are in line with previous reports of FTY use in patients that demonstrated a re-balanced distribution of $\mathrm{T}$ cells by virtue of decreased levels of effector $\mathrm{T}$ cells and increased levels of Treg cells [26-28]. However, a direct or DCindependent impact of FTY on T cell polarization or proliferation in vitro could not be demonstrated [29]. As APCs, and particularly DCs, are the most potent inducers and regulators of $\mathrm{T}$ cell responses, the potential modulation of DC function by FTY could be very powerful.

Upon activation and antigen uptake, DCs maturate, differentiate, and upregulate expression of surface markers such as CD83 or CD150 and co-stimulatory molecules including HLA-DR, CD86, CD80, or CD40. During FTY treatment in our patients, chiefly slanDCs, but also CD1 + DCs and monocytes, failed to maturate and express the co-stimulatory marker HLA-DR. This is in line with previous data $[16,21]$.
APCs that fail to differentiate or increase expression of their co-stimulatory markers have impaired antigen presentation and $\mathrm{T}$ cell activation properties, which may lead to decreased induction of pro-inflammatory Th1/ Th17 cell responses. CD86 is upregulated during the differentiation process on APCs, and there are some reports suggesting its relevance for induction of tolerance mechanisms in a range of immunological diseases [30]. In our analysis, the expression of CD86 was increased in slanDCs and CD1+ DCs. These data are in concordance with those previously presented for other DC subsets [14].

Our data suggest distinct but straightforward modulation of APC function by FTY treatment. In the literature, data on DC surface markers during FTY treatment have provided mixed results. Some studies did not find any impact on surface expression, particularly in in vitro studies $[15,16]$. Other findings are in line with our results $[14,24,31]$. Certainly, in our analyses, impact of FTY and FTYP on expression of co-stimulatory and maturation markers was more pronounced in ex vivo analyses compared to in vitro investigations. These differences may be explained by the relatively shorter exposure time for in vitro FTY and FTYP compared with in vivo experiments. Human DCs present a pattern of selective expression of S1PR1-4 with highest levels of S1PR4 on immature DCs $[16,25]$. Upon maturation, especially S1PR1 is upregulated whereas S1PR4 is slightly decreased and S1PR2-3 are almost unaffected [16, 32]. After FTY exposure, expression of S1PR1 and S1PR4 is reduced already after a short time period in human DCs [16]. Further reports demonstrated direct modulation of inflammatory and $\mathrm{T}$ cell stimulatory characteristics via S1PR4 [33, 34]. FTY acts as unselective S1PR agonist 
(a)

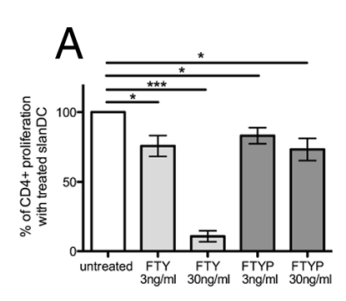

E

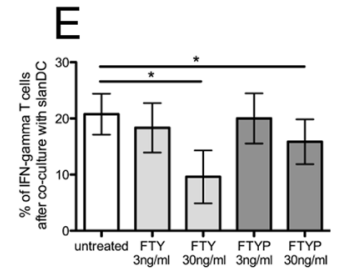

(b)

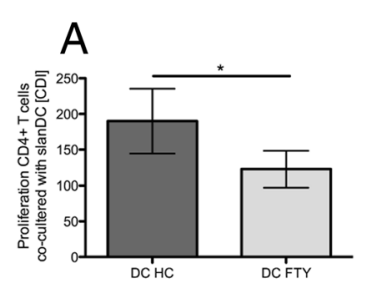

(c)

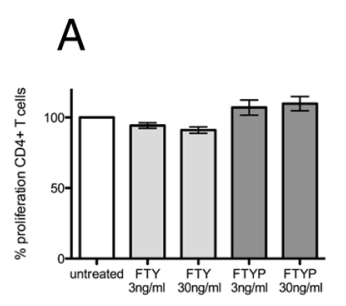

(d)

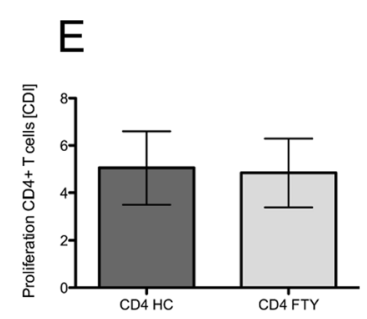

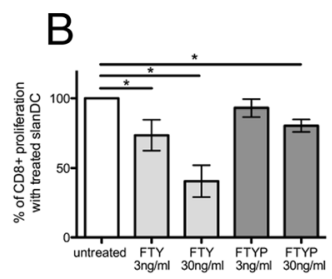

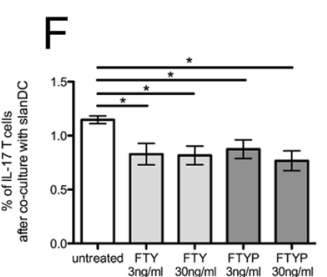

B

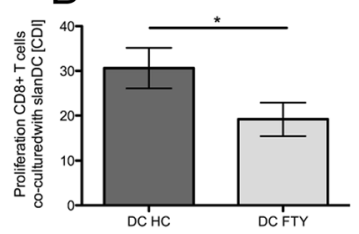

B

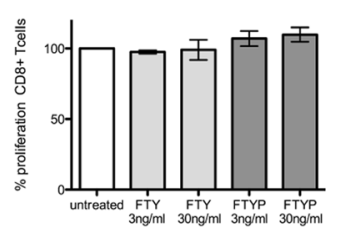

$\mathrm{F}$

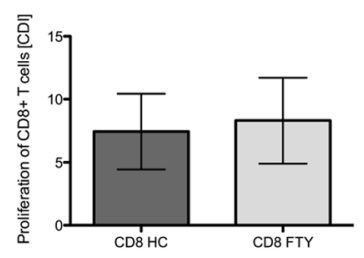

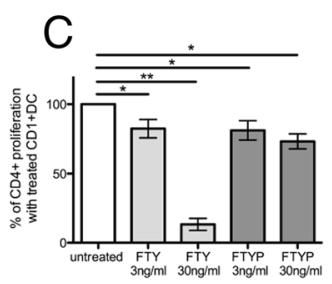

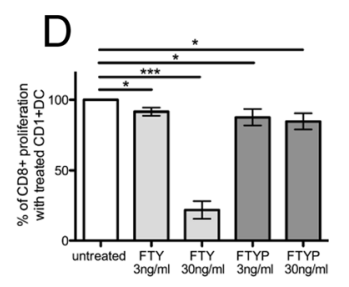

G

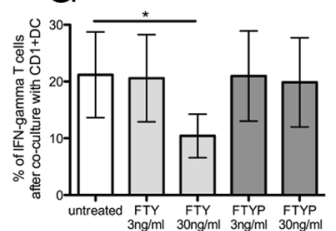

$\mathrm{H}$

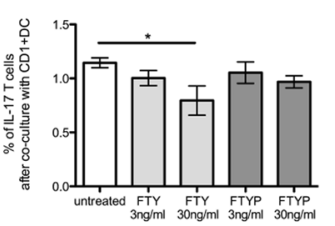

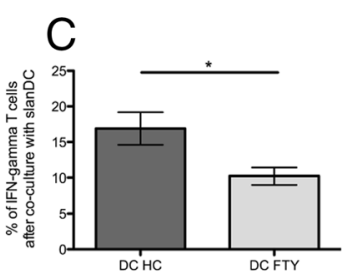

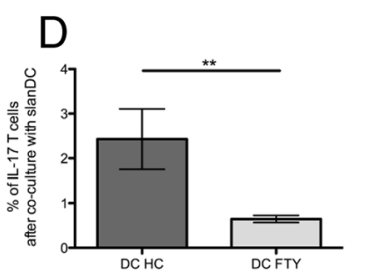

G
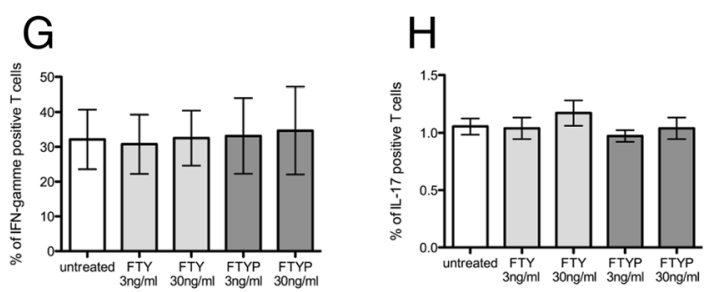

Fig. 3 (See legend on next page.) 
(See figure on previous page.)

Fig. 3 DC-dependent and independent T cell proliferation and programming. a SlanDCs or CD1+ DCs of healthy donors were pretreated with different concentrations of FTY or FTYP and co-cultured with allogeneic CFSE-labeled CD4+ or CD8+ T cells. DC-depending proliferation was calculated by CFSE-incorporation by flow cytometry and quantified by CDI. Proliferation after pretreatment is depicted in proportion to proliferation without pretreatment (A-D). SlanDCs or CD1+ DCs of healthy donors were pretreated with different concentrations of FTY or FTYP and co-cultured with allogeneic naïve CD4+ T cells. T cells were then analyzed regard their differentiation into pro-inflammatory IFN-gamma-expressing Th1 cells (E/F), IL-17-expressing Th17 cells (G/H). Mean values \pm SEM of eight individual experiments are presented. $\mathbf{b}$ In addition slanDCs of FTY-treated MS patients (DC FTY) and of healthy controls (DC HC) were co-cultured with allogeneic CFSE labeled CD4+ or CD8+ T cells of the same donor. DC-dependent proliferation was calculated by CFSEincorporation by flow cytometry and quantified by CDI (A/B). SlanDCs of FTY-treated RRMS patients (DC FTY) and healthy controls (DC HC) were cOcultured with allogeneic naiive CD4+ T cells of the same donor. T cells were then analyzed regard their differentiation into Th1 cells $(C)$ and Th17 cells $(D)$. Mean values \pm SEM of five different donors are presented. c DC-independent T cell proliferation and polarization. FTY-and FTYP-treated CFSE-labeled CD4+ or CD8+ $T$ cells of healthy donors were stimulated with human anti-CD3/CD28. Proliferation was calculated by CFSE-incorporation by flow cytometry and quantified by CDI (A-B). Polarization of FTY- and FTYP-treated naïve CD4+ T cells of healthy donors into IFN-gamma-expressing Th1 cells or IL-17expressing Th17 cells are depicted (G-H). Mean values \pm SEM of six individual experiments are presented. $\mathbf{d}$ In addition, proliferation of CD4+ or C8+ T cells of FTY-treated patients (CD4 FTY, CD8 FTY) compared to healthy controls (CD4 HC, CD8 HC) after anti-CD3/CD28 stimulation was evaluated (A/B). Asterisks indicate a statistically significant difference $\left({ }^{*} p<0.05,{ }^{* *} p<0.01,{ }^{* * *} p<0.001\right)$

affecting S1PR1-5. Interestingly, compared to FTY, findings on S1PR expression differ after treatment with selective S1PR agonists in human DCs [20]. These results indicate that impact of FTY on DCs is mediated by regulation of specific receptor expression profiles as well as direct intracellular signaling after S1PR agonism.

Interestingly, addition of S1P decreased surface expression of co-stimulatory molecules in slanDCs of healthy donors, leaving other APS subtypes unaffected. However, in FTY-treated patients, S1P-dependent modulation of surface markers on slanDCs was abrogated. These data further highlight slanDCs as distinct targets in modulation of S1P pathways via S1PR, and distinct from other APCs.

In addition to modulation of surface markers, further FTY-stimulated inhibition of pro-inflammatory cytokines was detected in slanDCs, CD1+ DCs, and monocytes both in vitro and ex vivo. Previous reports have shown a similar pattern of decrease of pro-inflammatory cytokines by fingolimod in murine bone marrow-derived DCs and induction of anti-inflammatory macrophages $[14,15,19,24]$. Furthermore and comparable to other reports in mice, phagocytic capacity was inhibited in FTYtreated slanDCs and monocytes in our study [15]. These results suggest that FTY impairs important DCs (a)

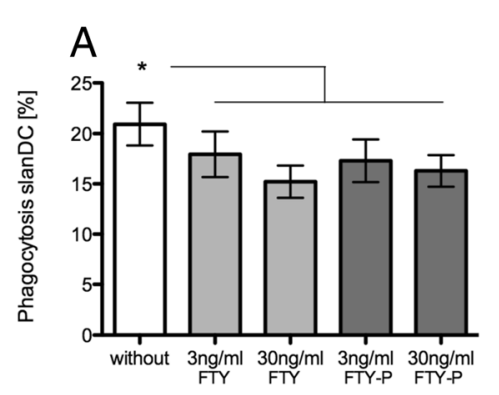

(b)

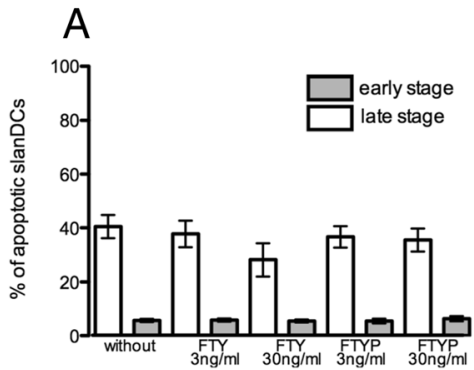

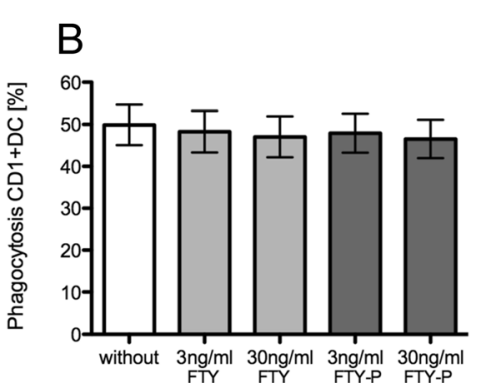

B

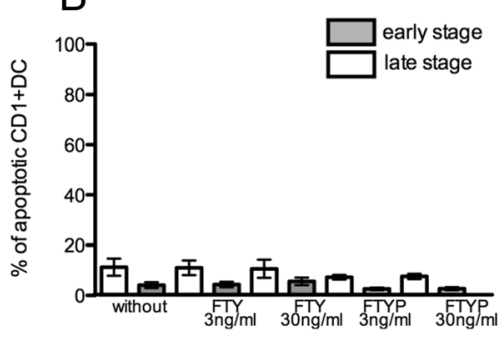

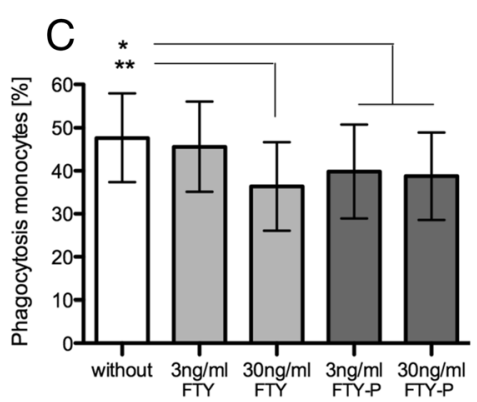

C

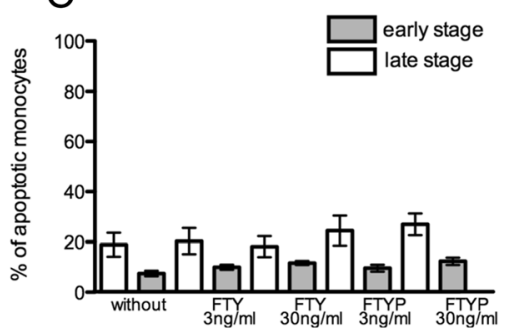

Fig. 4 Phagocytosis and apoptosis after FTY. a SlanDCs (A), CD1 + DCs (B), and monocytes $(C)$ were treated with different concentrations of FTY or FTYP before phagocytosis of carboxylate-modified yellow-green fluorescent beads was evaluated. Mean values \pm SEM of eight individual experiments are presented. Bonferroni's correction was used. Asterisks indicate a statistically significant difference $\left({ }^{*} p<0.05,{ }^{* *} p<0.01\right)$. b SlanDCs $(A)$, CD1+ DCs $(B)$, and monocytes ( $C$ ) were treated with different concentrations of FTY or FTYP for $24 \mathrm{~h}(A-C)$ or $48 \mathrm{~h}$ (data not shown).

Afterwards, apoptosis at early (gray bar) and late stage (white bar) was evaluated. Mean values \pm SEM of eight individual experiments are presented 
capabilities, which are important for antigen uptake and processing as well as the pro-inflammatory destructive demyelinating process of the CNS in MS pathology [15, 3538].

IL-12 and IL-23 are known as essential regulators in DC-depending Th1 and Th17 differentiation and programming. The relevance of sphingolipids in IL-12 and IL-23 secretion in DCs and decreased expression of IL-12 in bone marrow-derived DCs and monocytes-derived DCs after FTY has been already reported [15, 16, 18, 39-41]. However, slanDCs are one of the most potent inducers of Th17 and Th1 cells $[42,43]$. Our data demonstrate significant inhibition of IL-12 and IL-23 secretion after FTY exposure in vitro and ex vivo in slanDCs, but not in other DCs. In addition, we were able to demonstrate that FTY- or FTYP-treated slanDCs had reduced capacity to induce Th17 and Th1 cells as well as T cell proliferation in vitro. For the first time, these results could be confirmed in ex vivo experiments using slanDCs of FTY-treated patients. Th17 cells are known to be reduced in peripheral blood and CNS during FTY treatment [26-28]. Previous studies presented that S1PR4 on DCs is critically involved in promotion of Th17 cells [33].

We suggest that modulation of slanDCs by FTY treatment promotes the reduction of pro-inflammatory $\mathrm{T}$ cell activation and proliferation in MS. Effects on CD1+ DCs were less pronounced. Other studies have demonstrated a decrease in polarization of Th1 cells, but promotion of Th2 cells by FTY-treated monocytes-derived DCs [16, $18,19,44]$. Nevertheless, we could not identify increased activation of IL-4-producing Th2 cells by FTY-treated slanDCs or CD1+ DCs in vitro or ex vivo.

\section{Conclusions}

Our data demonstrate that S1PR-targeted therapies can act additionally as immunomodulators that affect the innate immune system beyond their established prominent effects on lymphocyte trafficking. Our results highlight that FTY can modulate essential DC-dependent pro-inflammatory $\mathrm{T}$ cell-mediated pathways in MS immunology, which could additionally contribute to the efficacy of FTY. These effects appear to develop over the first year of treatment, which is on a slower timescale than the instant effect of FTY on lymphocyte distribution. Other mechanisms of action are probably as well of importance because there is no direct link between absolute lymphocyte counts and therapeutic efficacy $[45,46]$. In summary, we present supportive data suggesting innate immune cells as additional important targets of S1PR-directed therapies for MS.

\section{Abbreviations}

APC: Antigen-presenting cells; CDI: Cell division index;

CFSE: Carboxyfluorescein-di-acetate-N-succinimidylester; CNS: Central nervous system; DC: Dendritic cells; FACS: Fluorescence-activated cell sorting; FCS: Fetal calf serum; FTY: Fingolimod; FTYP: Fingolimod-phosphate; IFN: Interferon; IL: Interleukin; MS: Multiple sclerosis; PBMC: Peripheral mononuclear cells; PBS: Phosphate-buffered saline; PMA: Phorbol myristate acetate; RRMS: Relapsing remitting multiple sclerosis; S1P: Sphingosine-1phosphate; S1PR: Sphingosine-1-phosphate receptor; Th cells: T helper cells; TNF-alpha: Tumor necrosis factor alpha; Treg cells: T regulatory cells

\section{Acknowledgements}

We thank M. Marggraf, N. Kretschmann, and S. Dartsch for the excellent technical assistance. Editorial support was provided by Nigel Eastmond of Eastmond Medicomm Ltd.

\section{Funding}

The study was supported in part by research funding from Novartis.

\section{Availability of data and materials}

T. Ziemssen has full access to all the data in the study and takes full responsibility for integrity of the data and the accuracy of the data analysis. Raw data are available on personal demand.

\section{Authors' contributions}

Study concept and design were contributed by KT and TZ. Acquisition of data was contributed by KT, UP, TS, and FAR-L. Analysis and interpretation of data were contributed by $K T, R H$, UP, and TS. Drafting of the manuscript was contributed by KT and TZ. Critical revision of the manuscript for important intellectual content was contributed by UP, FAR-L, and TZ. Statistical analysis was contributed by RH, KT and TS. Study supervision was contributed by TZ. All authors read and approved the final manuscript.

\section{Competing interests}

K. Thomas received personal compensation from Novartis, Biogen Idec, and Roche for the consulting service. T. Ziemssen received personal compensation from Biogen Idec, Bayer, Novartis, Sanofi, Teva, and Synthon for the consulting services. Ziemssen received additional financial support for the research activities from Bayer, Biogen Idec, Novartis, Teva, and Sanofi Aventis. T. Sehr, F.A. Rodriguez-Leal, R. Haase and U. Proschmann declare no competing interests.

\section{Consent for publication}

Not applicable.

\section{Ethics approval and consent to participate}

We further confirm that any aspect of the work covered in this manuscript that has involved human patients has been conducted with the ethical approval of all relevant bodies and that such approvals are acknowledged within the manuscript. The study was performed according to the Declaration of Helsinki, and the study protocol was approved by the Ethics Committee of the Faculty of Medicine of the Dresden University of Technology. The authors have received consent forms from any participants in the study and have these forms available in case they are requested by the editor.

Received: 15 December 2016 Accepted: 16 February 2017

Published online: 23 February 2017

\section{References}

1. Goverman J. Autoimmune T cell responses in the central nervous system. Nat Rev Immunol. 2009;9:393-407.

2. Mars LT, Saikali P, Liblau RS, Arbour N. Contribution of CD8 T lymphocytes to the immuno-pathogenesis of multiple sclerosis and its animal models. Biochim Biophys Acta. 1812;2011:151-61.

3. Nuyts AH, Lee WP, Bashir-Dar R, Berneman ZN, Cools N. Dendritic cells in multiple sclerosis: key players in the immunopathogenesis, key players for new cellular immunotherapies? Mult Scler. 2013;19:995-1002.

4. Steinman RM, Banchereau J. Taking dendritic cells into medicine. Nature. 2007:449:419-26.

5. Zozulya AL, Clarkson BD, Ortler S, Fabry Z, Wiendl H. The role of dendritic cells in CNS autoimmunity. J Mol Med (Berl). 2010;88:535-44.

6. Thomas K, Dietze K, Wehner R, Metz I, Tumani H, Schultheiss T, Gunther C, Schakel K, Reichmann H, Bruck W, et al. Accumulation and therapeutic 
modulation of 6-sulfo LacNAc(+) dendritic cells in multiple sclerosis. Neurol Neuroimmunol Neuroinflamm. 2014;1:e33.

7. Thomas K, Metz I, Tumani H, Bruck W, Ziemssen T. 6-sulfo LacNAc dendritic cells accumulate in various inflammatory, but not ischemic conditions of the central nervous system. Neuropathol Appl Neurobiol. 2016;42(4):394-8.

8. Gross CC, Jonuleit $\mathrm{H}$, Wiendl $\mathrm{H}$. Fulfilling the dream: tolerogenic dendritic cells to treat multiple sclerosis. Eur J Immunol. 2012;42:569-72.

9. Comabella M, Montalban X, Munz C, Lunemann JD. Targeting dendritic cells to treat multiple sclerosis. Nat Rev Neurol. 2010;6:499-507.

10. Cohen JA, Barkhof F, Comi G, Hartung HP, Khatri BO, Montalban X, Pelletier J, Capra R, Gallo P, Izquierdo G, et al. Oral fingolimod or intramuscular interferon for relapsing multiple sclerosis. N Engl J Med. 2010;362:402-15.

11. Kappos L, Radue EW, O'Connor P, Polman C, Hohlfeld R, Calabresi P, Selmaj K, Agoropoulou C, Leyk M, Zhang-Auberson L, Burtin P. A placebocontrolled trial of oral fingolimod in relapsing multiple sclerosis. N Engl J Med. 2010;362:387-401.

12. Chun J, Hartung HP. Mechanism of action of oral fingolimod (FTY720) in multiple sclerosis. Clin Neuropharmacol. 2010;33:91-101.

13. Arlt O, Schwiebs A, Japtok L, Ruger K, Katzy E, Kleuser B, Radeke HH. Sphingosine-1-phosphate modulates dendritic cell function: focus on nonmigratory effects in vitro and in vivo. Cell Physiol Biochem. 2014;34:27-44.

14. Luessi F, Kraus S, Trinschek B, Lerch S, Ploen R, Paterka M, Roberg T, PoisaBeiro L, Klotz L, Wiendl H, et al. FTY720 (fingolimod) treatment tips the balance towards less immunogenic antigen-presenting cells in patients with multiple sclerosis. Mult Scler. 2015;21:1811-22

15. Zeng X, Wang T, Zhu C, Xing X, Ye Y, Lai X, Song B, Zeng Y. Topographical and biological evidence revealed FTY720-mediated anergy-polarization of mouse bone marrow-derived dendritic cells in vitro. PLoS One. 2012;7:e34830.

16. Muller H, Hofer S, Kaneider N, Neuwirt H, Mosheimer B, Mayer G, Konwalinka G, Heufler C, Tiefenthaler M. The immunomodulator FTY720 interferes with effector functions of human monocyte-derived dendritic cells. Eur J Immunol. 2005:35:533-45.

17. Tsai HC, Han MH. Sphingosine-1-phosphate (S1P) and S1P signaling pathway: therapeutic targets in autoimmunity and inflammation. Drugs. 2016;76:1067-79.

18. von Wenckstern $\mathrm{H}$, Zimmermann $\mathrm{K}$, Kleuser B. The role of the lysophospholipid sphingosine 1-phosphate in immune cell biology. Arch Immunol Ther Exp (Warsz). 2006;54:239-51.

19. Rivera J, Proia RL, Olivera A. The alliance of sphingosine-1-phosphate and its receptors in immunity. Nat Rev Immunol. 2008;8:753-63.

20. Gollmann $\mathrm{G}$, Neuwirt $\mathrm{H}$, Tripp $\mathrm{CH}$, Mueller $\mathrm{H}$, Konwalinka G, Heufler C, Romani $\mathrm{N}$, Tiefenthaler M. Sphingosine-1-phosphate receptor type-1 agonism impairs blood dendritic cell chemotaxis and skin dendritic cell migration to lymph nodes under inflammatory conditions. Int Immunol. 2008;20:911-23.

21. Lan YY, Tokita D, Wang Z, Wang HC, Zhan J, Brinkmann V, Thomson AW. Sphingosine 1-phosphate receptor agonism impairs skin dendritic cell migration and homing to secondary lymphoid tissue: association with prolonged allograft survival. Transpl Immunol. 2008;20:88-94.

22. Czeloth N, Bernhardt G, Hofmann F, Genth H, Forster R. Sphingosine-1-phosphate mediates migration of mature dendritic cells. J Immunol. 2005;175:2960-7.

23. Lan YY, De Creus A, Colvin BL, Abe M, Brinkmann V, Coates PT, Thomson AW. The sphingosine-1-phosphate receptor agonist FTY720 modulates dendritic cell trafficking in vivo. Am J Transplant. 2005;5:2649-59.

24. Han Y, Li X, Zhou Q, Jie H, Lao X, Han J, He J, Liu X, Gu D, He Y, Sun E. FTY720 abrogates collagen-induced arthritis by hindering dendritic cell migration to local lymph nodes. J Immunol. 2015;195:4126-35.

25. Idzko M, Panther E, Corinti S, Morelli A, Ferrari D, Herouy Y, Dichmann S, Mockenhaupt M, Gebicke-Haerter P, Di Virgilio F, et al. Sphingosine 1phosphate induces chemotaxis of immature and modulates cytokinerelease in mature human dendritic cells for emergence of Th2 immune responses. FASEB J. 2002;16:625-7.

26. Serpero LD, Filaci G, Parodi A, Battaglia F, Kalli F, Brogi D, Mancardi GL, Uccelli A, Fenoglio D. Fingolimod modulates peripheral effector and regulatory $T$ cells in MS patients. J Neuroimmune Pharmacol. 2013;8:1106-13.

27. Chiba K, Kataoka H, Seki N, Shimano K, Koyama M, Fukunari A, Sugahara K Sugita T. Fingolimod (FTY720), sphingosine 1-phosphate receptor modulator, shows superior efficacy as compared with interferon-beta in mouse experimental autoimmune encephalomyelitis. Int Immunopharmacol. 2011:11:366-72.

28. Mehling M, Lindberg R, Raulf F, Kuhle J, Hess C, Kappos L, Brinkmann V. Th17 central memory T cells are reduced by FTY720 in patients with multiple sclerosis. Neurology. 2010;75:403-10.
29. Brinkmann V, Wilt C, Kristofic C, Nikolova Z, Hof RP, Chen S, Albert R, Cottens S. FTY720: dissection of membrane receptor-operated, stereospecific effects on cell migration from receptor-independent antiproliferative and apoptotic effects. Transplant Proc. 2001;33:3078-80.

30. Lutz MB, Schuler G. Immature, semi-mature and fully mature dendritic cells: which signals induce tolerance or immunity? Trends Immunol. 2002;23:445-9.

31. Martino A, Volpe E, Auricchio G, Izzi V, Poccia F, Mariani F, Colizzi V, Baldini PM. Sphingosine 1-phosphate interferes on the differentiation of human monocytes into competent dendritic cells. Scand J Immunol. 2007:65:84-91.

32. Bock S, Pfalzgraff A, Weindl G. Sphingosine 1-phospate differentially modulates maturation and function of human Langerhans-like cells. J Dermatol Sci. 2016;82:9-17.

33. Schulze T, Golfier S, Tabeling C, Rabel K, Graler MH, Witzenrath M, Lipp M. Sphingosine-1-phospate receptor $4(\mathrm{~S} 1 \mathrm{P}(4))$ deficiency profoundly affects dendritic cell function and TH17-cell differentiation in a murine model. FASEB J. 2011;25:4024-36.

34. Dillmann C, Ringel C, Ringleb J, Mora J, Olesch C, Fink AF, Roberts E, Brune B, Weigert A. S1PR4 signaling attenuates ILT 7 internalization to limit IFNalpha production by human plasmacytoid dendritic cells. J Immunol. 2016; 196:1579-90.

35. Benvenuti F, Hugues S, Walmsley M, Ruf S, Fetler L, Popoff M, Tybulewicz $\mathrm{VL}$, Amigorena S. Requirement of Rac1 and Rac2 expression by mature dendritic cells for T cell priming. Science. 2004;305:1150-3.

36. Bailey SL, Carpentier PA, McMahon EJ, Begolka WS, Miller SD. Innate and adaptive immune responses of the central nervous system. Crit Rev Immunol. 2006;26:149-88.

37. Lucchinetti CF, Parisi J, Bruck W. The pathology of multiple sclerosis. Neurol Clin. 2005;23:77-105. vi.

38. Lassmann $H$, Bruck W, Lucchinetti CF. The immunopathology of multiple sclerosis: an overview. Brain Pathol. 2007;17:210-8.

39. Schroder M, Richter C, Juan MH, Maltusch K, Giegold O, Quintini G, Pfeilschifter JM, Huwiler A, Radeke HH. The sphingosine kinase 1 and S1P1 axis specifically counteracts LPS-induced IL-12p70 production in immune cells of the spleen. Mol Immunol. 2011;48:1139-48.

40. Ceballos A, Sabatte J, Nahmod K, Martinez D, Salamone G, Vermeulen M, Maggini J, Salomon H, Geffner J. Sphingosylphosphorylcholine activates dendritic cells, stimulating the production of interleukin-12. Immunology. 2007;121:328-36.

41. Schaper K, Kietzmann M, Baumer W. Sphingosine-1-phosphate differently regulates the cytokine production of $\mathrm{IL}-12, \mathrm{IL}-23$ and $\mathrm{IL}-27$ in activated murine bone marrow derived dendritic cells. Mol Immunol. 2014:59:10-8.

42. Hansel A, Gunther C, Ingwersen J, Starke J, Schmitz M, Bachmann M, Meurer M, Rieber EP, Schakel K. Human slan (6-sulfo LacNAc) dendritic cells are inflammatory dermal dendritic cells in psoriasis and drive strong $\mathrm{TH} 17 / \mathrm{TH}$ T-cell responses. J Allergy Clin Immunol. 2011;127:787-94. e781-789.

43. Schakel K, von Kietzell M, Hansel A, Ebling A, Schulze L, Haase M, Semmler C, Sarfati M, Barclay AN, Randolph GJ, et al. Human 6-sulfo LacNACexpressing dendritic cells are principal producers of early interleukin-12 and are controlled by erythrocytes. Immunity. 2006;24:767-77.

44. Martino V, Tonelli R, Montemurro L, Franzoni M, Marino F, Fazzina R, Pession A. Down-regulation of MLL-AF9, MLL and MYC expression is not obligatory for monocyte-macrophage maturation in AML-M5 cell lines carrying $t(9$; 11)(p22;q23). Oncol Rep. 2006;15:207-11.

45. Giovannoni G, de Jong B, Derfuss T, Izquierdo G, Mazibrada G, Molyneux P, Nicholas R, Overell J, Ziemssen T, Juliusson G. A pragmatic approach to dealing with fingolimod-related lymphopaenia in Europe. Mult Scler Relat Disord. 2014:4:83-84.

46. Thomas K, Ziemssen T. Management of fingolimod in clinical practice. Clin Neurol Neurosurg. 2013:115:S60-S64. 